\title{
Fractographic analysis of fractures of graphitized cast iron using optical microscopy
}

\author{
K.V. Makarenko, A.A. Nikitin, A.S. Parenko \\ makkon1@yandex.ru|zzzalexzzz95@gmail.com|3dprintense@gmail.com \\ BSTU, Bryansk, Russian Federation
}

\begin{abstract}
Fractography - methods for studying material fractures, the science of the structure of fracture surfaces. Fractography is widely used to determine the causes of destruction of materials and structures. In materials sciences, fractography is used to study crack propagation, microstructure studies, and quality control. When investigating the failure of structures, determining the type of crack (material fatigue, hydrogen embrittlement, stress corrosion cracking, exceeding the permissible load, etc.) makes it possible to determine the cause of the failure. Fractographic studies include the study of a fracture with the naked eye, using an optical and electron microscope. Other methods are also often used, such as measuring hardness or studying the distribution of chemical elements using $X$ ray spectral microanalysis. Fractographic (or fracture) analysis is the first and obligatory stage of research that must be performed by an expert of the metallurgical examination laboratory when determining the causes of material destruction. Visual examination of the fracture (fracture) surface makes it possible to establish the location of the beginning of fracture, the nature of its further course, to make a judgment about the degree of plasticity of the material and about possible structural defects that led to the initiation and development of cracks. The use of fractographic analysis methods for reconstructing the fracture surface of graphitized cast iron is proposed. The influence of various inclusions in the structure of cast iron is considered. A study of the fracture surface of graphitized cast irons was carried out, and the causes affecting the fracture process were identified.
\end{abstract}

Keywords: cast iron, graphite, fracture, fractographic analysis.

\section{Introduction}

Fractography as a method for learning fracture's is widely used in examinations to identify the causes of the destruction of various parts of machines and objects. Traditionally, scanning electron microscopy is used for these purposes [1-3]. A distinctive feature of the imaging of which is the use of secondary electrons. These secondary electrons generated by the material make it possible to obtain an image of objects with complex geometry like a fractures of surfaces.

A traditional optical microscope, unlike a scanning electron microscope, does not have a sufficiently extended focus depth. This does not allow the traditional microscope to obtain focused images simultaneously for the peaks and troughs of broken surfaces [4].

Depth of field (DOF) of the microscope objective - is its ability to maintain the desired image (spatial frequency at a given contrast) quality without refocusing if the subject is closer and farther from the best focus [5]. DOF is also applied to objects with complex geometry or features of varying heights. DOF (T) can be expressed as follows:

$$
T=\frac{250}{N^{2}}+\frac{250 \varepsilon}{A N}+\frac{n \lambda}{2 A^{2}}
$$

where $\varepsilon \approx 2-$ minimum angular resolution of the eye; $N-$ useful increase; $A$ - lens aperture; $n$ - refractive index; $\lambda$ light wavelength. DOF becomes smaller as the numerical aperture and microscope increase (for example, for white light $T=54 \mu \mathrm{m}$ at $A=0,17, N=90$ and $T=0,6 \mu \mathrm{m}$ at $A=1,25$, $N=1080$ ). These numbers characterize the height of those structural details that can be examined with a single microscope setup.

Modern digital microscopes based on the use of traditional optical systems using specialized software make it possible to solve the problems of fractographic analysis without the use of expensive electron microscopes [6-8].

The aim of the article is to demonstrate the capabilities of digital optical microscopy in conjunction with the developed image processing algorithms for obtaining fractographic images of fractures of the surfaces of graphitized cast irons.

\section{Research methodology}

Test specimens were made from graphitized cast iron smelted in induction furnaces. The melt was modified by magnesium in an autoclave to obtain spherical graphite in it. Gray cast iron modification was carried out in a ladle by ferrosilicon. The chemical composition of graphitized cast irons is presented in table 1 .

Table 1. The chemical composition of the cast irons

\begin{tabular}{|c|c|c|c|c|c|c|c|c|c|c|}
\hline \multirow{2}{*}{ Cast iron class } & \multicolumn{10}{|c|}{ Content elements $\%$} \\
\hline & $\mathrm{C}$ & $\mathrm{Si}$ & $\mathrm{Mn}$ & $\mathrm{S}$ & $\mathrm{P}$ & $\mathrm{Cr}$ & $\mathrm{Ni}$ & Mo & $\mathrm{Cu}$ & $\mathrm{Mg}$ \\
\hline \begin{tabular}{|l|} 
high strength \\
\end{tabular} & 3,5 & 2,4 & 1,0 & 0,02 & 0,04 & 0,4 & 1,3 & 0,7 & 0,35 & 0,05 \\
\hline gray & 3,1 & 1,6 & 1,3 & 0,06 & 0,4 & 0,3 & 0,4 & - & - & - \\
\hline
\end{tabular}

After modification, cast irons were poured into dry sand-clay molds to obtain solid sleeve castings $\varnothing 130 \mathrm{~mm}$.

From castings of high-strength and gray cast iron on a lathe, blanks of rings with a section of $6 \times 3,5 \mathrm{~mm}$ and $6 \times 5$ $\mathrm{mm}$ were cut. The castle was cut in the rings. In order to reduce the influence of segregation phenomena, the rings were subjected to heat treatment. Heat treatment for rings of ductile and gray cast iron: austenitization temperature $850^{\circ} \mathrm{C}$, holding time $60 \mathrm{~min}$; air cooling to room temperatures; tempering $410^{\circ} \mathrm{C}$ for $60 \mathrm{~min}$.

After heat treatment, microstructural research and tests of mechanical properties were carried out (table 2). Bending test of heat-treated rings was carried out in accordance with the scheme shown in the fig. 1. 
Table 2. The research results of cast iron rings

\begin{tabular}{|c|c|c|c|c|c|c|c|}
\hline \multirow{3}{*}{ Cast iron class } & \multicolumn{5}{|c|}{ GOST 3443-87 structure } & \multicolumn{2}{|c|}{ Mechanical properties } \\
\hline & \multicolumn{4}{|c|}{ Graphite } & \multirow{2}{*}{ Metal matrix } & \multirow{2}{*}{ hardness } & \multirow{2}{*}{$\sigma, \mathrm{MPa}$} \\
\hline & Size & Form & Distribution & Amount & & & \\
\hline High-strength & ШГд4 & ШГф3 & ШГр3 & ШГ4 & Tempered troostite & 280 & 130,6 \\
\hline Gray & ПГд45-ПГд90 & ПГф1 & ПГр1 & ПГ6 & $\begin{array}{l}\text { Tempered troostite; } \\
\text { phosphide eutectic }\end{array}$ & 270 & 60,5 \\
\hline
\end{tabular}

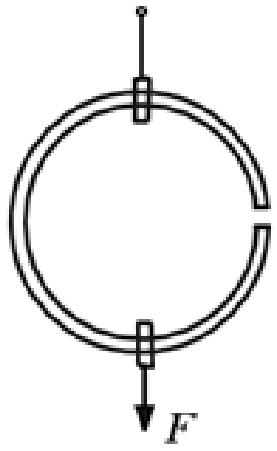

Fig. 1. Loading scheme

For 3-dimensional reconstruction of fracture surfaces, a layer-by-layer microscopy method was used. The method allows to obtain topographic reliefs of volumetric objects based on information from partially sharp images. To do this, using a digital microscope, we recorded images of the microstructure of the fracture surface with a certain depth step. The study and registration of the microstructure was carried out on an analytical computerized complex, which was created on the basis of an inverted Leica DM IRM metallographic microscope. A number of such images are presented in Fig. 2.

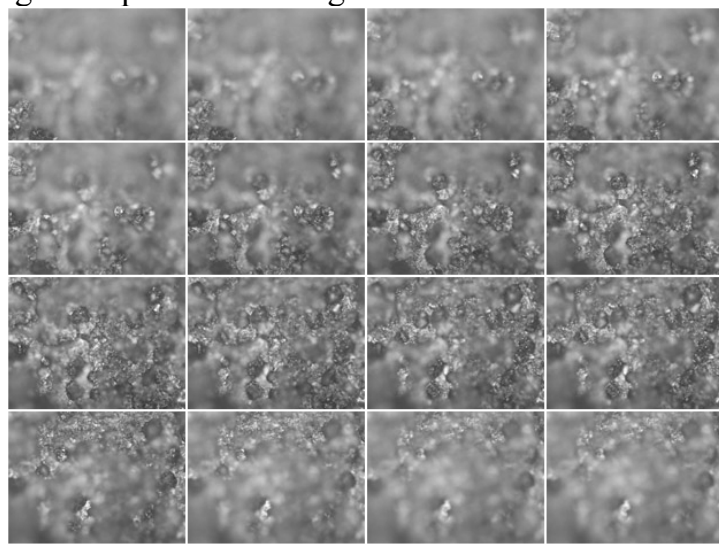

Fig. 2. The initial series of images of fracture of a sample of high-strength cast iron with spherical graphite with a depth step of $8 \mu \mathrm{m}, \times 200$

Optical Reconstruction 3D (OptiRec3D - developer Ph.D. Chmykhov D.V. (FSBEI BO BSTU)) software was used to reconstruct the surface of cast iron fracture from the initial series of previously obtained images. The program performs volumetric reconstruction of the surface by a set of photographs of one object photographed with a given depth step. OptiRec3D has a good source data processing speed and high accuracy of reconstructed models. An example of the volume surface of a fracture of a sample of High-strength cast iron with nodular graphite is presented in Fig. 3 .

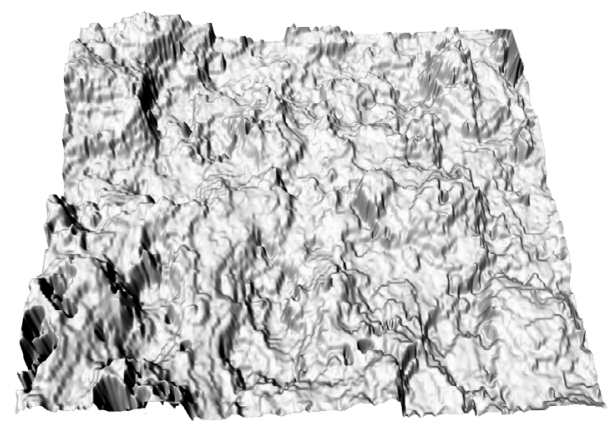

Fig. 3. The fracture surface of ductile iron obtained using the optical reconstruction program OptiRec3D

To obtain a fracture image of the surface of graphitized gray and ductile iron, a set of photographs of microstructures was used. Image spacing $8 \mu \mathrm{m}$ for Highstrength cast iron and $12 \mu \mathrm{m}$ for gray iron. The pixel size in the images was determined by the increase in the lens, in both cases it was $0.637 \mu \mathrm{m}$. The fracture surface of High-strength cast iron with a surface image (Fig. 4) is shown in Fig. 5.

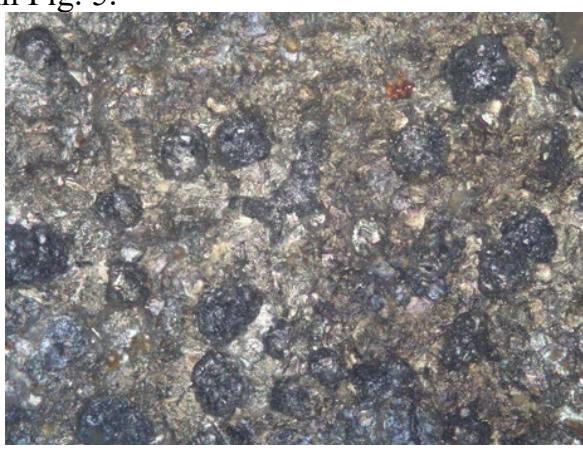

Fig. 4. The microstructure of the fracture surface of a sample of High-strength cast iron with spherical graphite, obtained by summing up areas with high definition from various images of a number of data (etching with $4 \%$ alcohol solution of nitric acid), $\times 200$

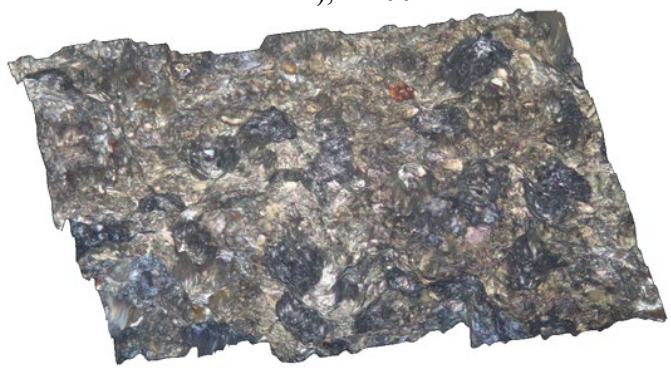

Fig. 5. The fracture surface of a sample of high-strength cast iron with spherical graphite with an overlaid image of its microstructure

The fracture structure of gray cast iron with lamellar graphite after various stages of the surface reconstruction operation is shown in Fig. 6. 


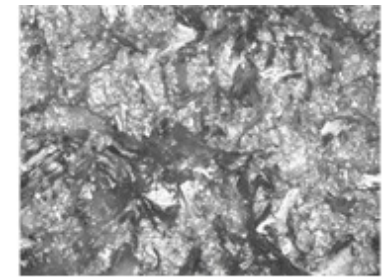

a)

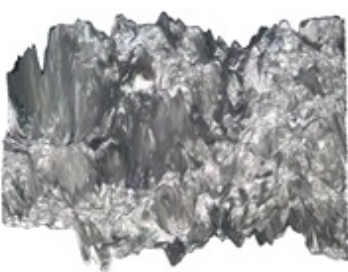

b)

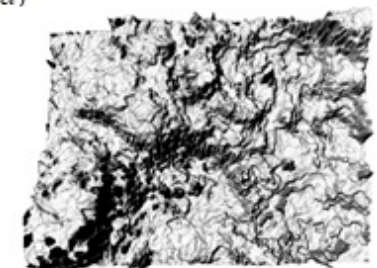

c)

Fig. 6. The fracture surface of gray cast iron with lamellar graphite: a - surface microstructure $\times 200$; $b$ - volumetric reconstruction of the surface with the applied microstructure; $\mathrm{c}$ model of fracture surface obtained using OptiRec3D software

The fracture surface of gray cast iron (Figure 6, b) is characterized by a rougher structure and a pronounced relationship with the location of the graphite phase than that of a sample of high-strength cast iron. An analysis of the image of the fracture surface shows that cracks in the fracture process mainly formed along the planes of graphite inclusions (Figure 6, a). The observed picture indicates that the destruction passed through the centers of the eutectic colonies, where the graphite inclusions have the largest transverse dimensions. In these areas of cast iron, the metal matrix is strongly fragmented by the graphite phase.

\section{The discussion of the results}

Analysis of the fracture surface shows that nonmetalic inclusions also contributed to the destruction of gray cast iron. Greater pollution of cast iron by sulfur and additional doping with phosphorus lead to the appearance of sulfide inclusions and regions with phosphide eutectics in the structure, which, like graphite, are stress concentrates.

Phosphide eutectic and sulfide inclusions in the structure of cast iron are usually concentrated on the periphery of eutectic colonies. In these areas on the surface model (Figure 6, b) peaks and troughs are observed, indicating that the destruction occurred precisely on these structural elements. The negative effect of phosphide eutectic is explained by the fact that it, hardening at the last stage of crystallization, isolates individual eutectic cells, thereby creating interfaces in the structure. The interface, as well as graphite plates, violate the continuity and uniformity of the metal matrix. Cementite inclusions present in phosphide eutectic increase its hardness and contribute to brittle fracture. Thus, a crack in gray cast iron can pass either through eutectic cells along the graphite planes, or bypassing them and collapsing along sulfide inclusions or regions of phosphide eutectic.

Despite the fact that graphite inclusions in high-strength cast iron have the shape of spheroids, and this, according to numerous authors, significantly weakens their negative impact on mechanical properties, the features of their distribution, as shown above, affect the mechanism of cast iron fracture. When studying the microstructure of the fracture surface of high-strength cast iron (Figure 4), it is noteworthy that the fracture surface passes along the chains of graphite inclusions. Analysis of the fracture surface shows that it is precisely along the cluster chains of eutectic cells that cast iron is destroyed.

The destruction of High-strength cast iron rings takes place in several stages. At the initial stage, the nucleation of cracks begins at the boundary "graphite - metal matrix", because, despite their compact form, graphite inclusions separate the metal matrix of cast iron. Then, the process of separation of the structure is localized by plastic deformation of the metal matrix. At this stage, the development of microcracks follows the paths of least resistance along those sections of the metal matrix that are between two adjacent graphite inclusions. The weakening of the metal matrix occurs as a result of the occurrence in the structure of isthmuses between adjacent graphite inclusions combined into cluster chains. Figure 4 shows that the graphite inclusions emerging on the fracture surface are interconnected and form "strings" along which the crack propagates during fracture. Moreover, in the process of fracture, graphite inclusions often remain intact, which indicates the existence of a gap between graphite and a metal matrix. At the final stage, the fusion of microcracks begins and the destruction of cast iron occurs.

In high-strength cast iron, nonmetalic inclusions are much smaller than in gray cast iron, so their effect on the destruction processes is reduced. When studying the surface structure of fracture of ductile iron (Figure 5), there are practically no peaks and depressions, which, as previously shown, for gray iron are parts of the structure where nonmetallic inclusions are located. The reason of this is that the contained in the ligature magnesium used to modify cast iron is partially spent on desulfurization, binding sulfur to a compound removed with slag

Research of fracture surfaces of graphitized cast irons prove that the destruction processes are influenced not only by the shape, but also by the distribution of the graphite phase.

\section{Conclusion}

The results of using a modern digital optical microscope in combination with specialized software presented in the article made it possible to obtain highquality fractograms of fractures of graphitized cast irons. The results demonstrated a high degree of adequacy and allowed us to assess the relationship between the structure of the material and the processes of destruction The potential inherent in this method will expand the capabilities of traditional optical microscopy and is an excellent alternative to expensive scanning electron microscopy.

\section{References:}

[1] Stremel, M.A. Possibilities of fractography / M.A. Stremel / Metallurgy and heat treatment of metals. 2005. - No. 5 (599). - pp. 35-43.

[2] Stremel, M.A. On the analysis of images in fractography (methodological notes) / M.A. Stremel / Deformation and fracture of materials. - 2015. - No. 10. - pp. 2-9. 
[3] Strelnikov, I.V. Quality issues of plasma spot welding: metallography, fractography, statistics / I.V. Strelnikov, A.V. Konovalov, F. Stempfer / Welding and diagnostics. - 2010. - No. 5. - pp. 47-50.

[4] Clarke, A.R. Microscopy Techniques for Materials Science / A.R. Clarke, C.N. Eberhardt. - England, Cambridge: Woodhead Publishing Limited, 2002. $459 \mathrm{p}$.

[5] Wu, Q Microscope Image Processing / Qiang Wu, Fatima A. Merchant, Kenneth R. Castleman. England, London: Elsevier, 2008. - 548 p.

[6] Makarenko, K.V. Fractal Analysis of Morphological Parameters of the Structure Materials / K.V. Makarenko, A.A. Nikitin // CEUR Workshop Proceeding of the 9th International Conference on Computer Graphics and Vision (GraphiCon 2019). Vol. 2485. - pp. 240-243.

[7] Panteleev, V.G. Computer microscopy / V.G. Panteleev, O.V. Egorova, E.I.Klykova. - M: Technosphere, 2005. - 304 p.

[8] Zentsova, EA Digital optical microscopy / E.A. Zentsova // In the collection: Innovations, quality and service in engineering and technology Collection of scientific papers of the $5^{\text {th }}$ International Scientific and Practical Conference. - 2015 - pp. 150-153.

\section{About the authors}

Makarenko Konstantin V., Doctor of Technical Sciences, Professor, Department of Engineering and Materials Science, Bryansk State Technical University. E-mail: makkon1@yandex.ru.

Nikitin Alexander A., graduate student of the Department of Tribotechnical Materials Science and Materials Technology, Bryansk State Technical University. Email: zzzalexzzz95@gmail.com.

Parenko Andrei S., graduate student of the Department of Tribotechnical Materials Science and Materials Technology, Bryansk State Technical University. Email: 3dprintense@gmail.com 